\title{
Delphinidin induces cytotoxicity and potentiates cytocidal effect in combination with arsenite in an acute promyelocytic leukemia NB4 cell line
}

\author{
BO YUAN ${ }^{1,3}$, SAKI OKUSUMI $^{1}$, YUTA YOSHINO ${ }^{1}$, CHIHIRO MORIYAMA $^{1}$, \\ SACHIKO TANAKA $^{2}$, TOSHIHIKO HIRANO ${ }^{2}$, NORIO TAKAGI ${ }^{3}$ and HIROO TOYODA ${ }^{1}$ \\ Departments of ${ }^{1}$ Clinical Molecular Genetics, ${ }^{2}$ Clinical Pharmacology, and ${ }^{3}$ Applied Biochemistry, \\ School of Pharmacy, Tokyo University of Pharmacy and Life Sciences, Hachioji, Tokyo 192-0392, Japan
}

Received February 25, 2015; Accepted April 2, 2015

DOI: $10.3892 /$ or.2015.3963

\begin{abstract}
The effects of delphinidin were investigated by focusing on growth inhibition, cell cycle arrest and apoptosis induction in the human acute promyelocytic leukemia (APL) NB4 cell line. Delphinidin exhibited a dose- and time-dependent cytotoxic effect against NB4 cells. Almost no cell cycle arrest, but an apparent increase in the percentage of sub- $\mathrm{G}_{1}$ cells was observed in delphinidin-treated cells. The activation of caspase- 8 and -9 was observed as early as 1-h post-exposure to delphinidin, followed by the activation of caspase-3 from 3-h post-exposure. A substantial decrease in the expression level of Bid was also observed as early as 1-h post-exposure. A modest decrease in the mitochondrial membrane potential $(\Delta \Psi \mathrm{m})$ was observed at 3-h post-exposure, followed by a substantial time-dependent decrease in $\Delta \Psi \mathrm{m}$ in treated cells. Delphinidin exerted more potent cytotoxicity against NB4 cells than normal peripheral blood mononuclear cells (PBMNCs). In addition, delphinidin in combination with an arsenic derivative arsenite $\left(\mathrm{As} \mathrm{s}^{\mathrm{III}}\right)$, which has demonstrated marked efficacy in patients with APL, achieved an enhanced cytocidal effect against NB4 cells, but lesser on PBMNCs. Treatment of NB4 cells with As ${ }^{\mathrm{III}}$ plus delphinidin did not increase, but decreased slightly, intracellular arsenic accumulation (As[i]) as compared to that treated with $\mathrm{As}^{\mathrm{III}}$ alone. These results suggested that delphinidin selectively sensitized NB4 cells to As ${ }^{\mathrm{III}}$, resulting in the enhancement of As ${ }^{\mathrm{III}}$ cytotoxicity by strengthening intrinsic/extrinsic pathwaymediated apoptosis induction, rather than affecting the As[i] levels. These observations may offer a rationale for the use of delphinidin to improve the clinical efficacy of $\mathrm{As}^{\mathrm{III}}$.
\end{abstract}

Correspondence to: $\mathrm{Dr}$ Bo Yuan, Department of Applied Biochemistry, School of Pharmacy, Tokyo University of Pharmacy and Life Sciences, 1432-1 Horinouchi, Hachioji, Tokyo 192-0392, Japan E-mail: yuanbo@toyaku.ac.jp

Key words: delphinidin, acute promyelocytic leukemia, NB4, apoptosis, cell-cycle arrest, arsenite

\section{Introduction}

Acute promyelocytic leukemia (APL) is characterized by a balanced reciprocal translocation between chromosomes 15 and 17, resulting in the fusion of promyelocytic leukemia (PML) and retinoic acid receptor $\alpha(\operatorname{RAR} \alpha)$ (1-3). Administration of arsenic trioxide (arsenite, $\mathrm{As}^{\mathrm{III}}$ ), an arsenic derivative, has demonstrated marked therapeutic efficacy in the treatment of relapsed and refractory APL patients. In order to understand the mode of action of $\mathrm{As}^{\mathrm{III}}$ and provide an effective treatment protocol for individual APL patients, studies have been conducted on the pharmacokinetics of $\mathrm{As}^{\mathrm{III}}$ in APL patients using biological samples such as urine, blood and cerebrospinal fluid (4-7). In this regard, we have clarified the distribution of arsenic metabolites in, not only peripheral blood and cerebrospinal fluid, but also bone marrow from APL patients who had received the consecutive administration of $\mathrm{As}^{\mathrm{III}}(5,7,8)$. The findings on the pharmacokinetics of As ${ }^{\mathrm{III}}$ in APL patients provide novel insight into the clinical applications of $\mathrm{As}^{\mathrm{III}}$, and may contribute to improved therapeutic protocols (9).

Although the clinical efficacy of As ${ }^{\text {III }}$-based regimens against APL has been reported $(6,10)$, side-effects of As ${ }^{I I I}$ remain a serious concern and limit its clinical applications. Application of new $\mathrm{As}^{\mathrm{III}}$-based therapies may require the generation of sensitizing strategies for improving the efficacy of $\mathrm{As}^{\mathrm{III}}$ as well as minimizing its side-effects. In this regard, there is emerging interest in the chemotherapeutic application of natural substances, such as tea polyphenols and resveratrol, for cancer treatment (11). Specifically, flavonoids such as quercetin and genistein have been reported to potentiate the apoptotic action of As ${ }^{\mathrm{III}}$ in leukemic cell lines, such as HL-60, U937 and THP-1 $(12,13)$.

Delphinidin (Fig. 1), a major anthocyanidin known to be present in pigmented fruits and vegetables such as pomegranates, berries, dark grapes, eggplants and red onions, is a diphenylpropane-based polyphenolic ring structure that carries a positive charge in its central ring (14). Delphinidin has gained considerable attention as it appears to possess strong antioxidant/oxidant properties as well as other potentially beneficial characteristics, such as anti-inflammatory, antimutagenic, antiangiogenic, and anti-adipocyte differen- 
<smiles></smiles>

Figure 1. Chemical structure of delphinidin.

tiation activities (15-20). Treatment with delphinidin resulted in a reduction of cells in $\mathrm{G}_{1}$ phase and an accumulation in $\mathrm{G}_{2} / \mathrm{M}$ phase in human HeLa uterine carcinoma cell line, and human CaCo-2 colorectal carcinoma cell line, accompanied by apoptosis induction (18). Yun et al (17) also demonstrated that delphinidin suppresses the NF- $\kappa \mathrm{B}$ pathway, resulting in $\mathrm{G}_{2} / \mathrm{M}$ phase arrest and apoptosis induction in human HCT116 colon cancer cell line and human PC3 prostate cancer cell line (15). Despite investigations into the antitumor activity of delphinidin against various types of cancer cells derived from solid tumors $(15-19,21,22)$, to the best of our knowledge, few studies have been conducted to investigate the effects of delphinidin on leukemic cells $(23,24)$. Although delphinidin and its glycosides have been shown to trigger apoptosis in non-APL HL-60 (PML-RAR $\alpha$ negative) cells through a ROS/ JNK-mediated mitochondrial death pathway $(23,25)$, the effects of delphinidin on the human APL cell line harboring PML-RAR $\alpha$ remain largely unclear.

In the present study, the effects of delphinidin were investigated by focusing on growth inhibition, cell-cycle arrest and apoptosis induction in the APL NB4 cell line (PML-RAR $\alpha$ positive). Furthermore, the cytocidal effects of delphinidin in combination with $\mathrm{As}^{\mathrm{III}}$ were assessed to explore a potential application of delphinidin as an effective chemopreventive and/or chemotherapeutic agent for $\mathrm{As}^{\mathrm{III}}$-based therapy in patients with hematologic malignancies.

\section{Materials and methods}

Materials. Sodium arsenite (As $\left.{ }^{\mathrm{III}}\right)$ was purchased from Tri Chemical Laboratories (Yamanashi, Japan). Delphinidin, RPMI-1640 medium, propidium iodide (PI), ribonuclease A (RNase A) and 2,3-bis(2-methoxy-4-nitro-5-sulfophenyl)-5[(phenylamino)carbonyl]-2H-tetrazolium hydroxide (XTT) were purchased from Sigma-Aldrich (St. Louis, MO, USA). Fetal bovine serum (FBS) and phenazine methosulfate (PMS) were obtained from Nichirei Biosciences (Tokyo, Japan) and Wako Pure Chemical Industries (Osaka, Japan), respectively.

Cell lines and culture conditions. NB4, a human APL cell line with $\mathrm{t}(15 ; 17)$, was obtained from the Deutsche Sammalung von Mikroorganismen und Zellkulturen $\mathrm{GmbH}$ (Braunschweig, Germany). Peripheral blood mononuclear cells (PBMNCs) were isolated from three healthy volunteers using Histopaque-1077 (Sigma-Aldrich) according to the method previously described (26). Briefly, $3 \mathrm{ml}$ of heparinized blood was mixed with $5 \mathrm{ml}$ of phosphate-buffered saline (PBS), and loaded on $3 \mathrm{ml}$ of Histopaque-1077. After centrifugation at $400 \mathrm{x} \mathrm{g}$ for $30 \mathrm{~min}$ at room temperature, the opaque interface containing PBMNCs was transferred to a clean centrifuge tube and washed three times with PBS. The two types of cells were cultured in RPMI-1640 medium supplemented with $10 \%$ heatinactivated FBS and $100 \mathrm{U} / \mathrm{ml}$ of penicillin and $100 \mu \mathrm{g} / \mathrm{ml}$ of streptomycin (Wako Pure Chemical Industries) at $37^{\circ} \mathrm{C}$ in a humidified atmosphere at $5 \% \mathrm{CO}_{2}$ in air. For experiments, the cell density of NB4 and PBMNCs was adjusted to $1 \times 10^{5} \mathrm{ml}$ and $5 \times 10^{5}$ cells $/ \mathrm{ml}$, respectively, prior to the treatments. The present study was approved by the IRB Committee of Tokyo University of Pharmacy and Life Sciences. Informed consent was obtained from all the healthy volunteers.

XTT assay. Cell viability was determined by an XTT dye-reduction assay according to the method previously described (27). Briefly, after treatment with various concentrations of delphinidin and $\mathrm{As}^{\mathrm{III}}$, alone or in combination, for a designated time, the cells were washed with PBS twice and resuspended in an appropriate volume of PBS. An aliquot $(0.2 \mathrm{ml})$ of cell suspension was inoculated into 96-well plates (Iwaki, Tokyo, Japan) followed by the addition of $50 \mu \mathrm{l}$ XTT/PMS mixed solution (1.5 mM XTT and $0.025 \mathrm{mM}$ PMS). After incubation at $37^{\circ} \mathrm{C}$ for $4 \mathrm{~h}$, the plates were mixed on a mechanical plate shaker, and absorbance at $450 \mathrm{~nm}$ was measured using a microplate reader (Safire; Tecan, Männedorf, Switzerland). The relative cell viability was expressed as the ratio of the absorbance of each treatment group against that of the corresponding untreated control group. The $\mathrm{IC}_{50}$ value of delphinidin was calculated from the cell proliferation inhibition curve. Data are shown as means \pm SD from three independent experiments.

Cell cycle analysis. After treatment with the $\mathrm{IC}_{50}$ value of delphinidin at $14.0 \mu \mathrm{M}$ for $24 \mathrm{~h}$, a cell cycle analysis was performed using a FACSCanto flow cytometer (Becton-Dickinson, San Jose, CA, USA) according to a method previously described, with modifications (26). To stain cellular DNA, the cells were washed twice with PBS, fixed with $1 \%$ paraformaldehyde/ PBS for $30 \mathrm{~min}$, washed twice again with PBS, permeabilized in $70 \%(\mathrm{v} / \mathrm{v})$ cold ethanol and kept at $-20^{\circ} \mathrm{C}$ for at least $4 \mathrm{~h}$. The cell pellets were washed twice with PBS after centrifugation and incubated with $0.25 \%$ Triton-X 100 for 5 min on ice. After washing with PBS, the cells were centrifuged and resuspended in $500 \mu 1$ of PI/RNase A/PBS $(5 \mu \mathrm{g} / \mathrm{ml} \mathrm{PI}$ and $0.1 \%$ RNase A in PBS) and incubated for $30 \mathrm{~min}$ in the dark at room temperature. A total of 10,000 events were obtained and Diva software (Becton-Dickinson) and ModFit LT ${ }^{\mathrm{TM}}$ ver.3.0 (Verity Software House, Inc., Topsham, ME, USA) were used to calculate the number of cells at each sub- $\mathrm{G}_{1}, \mathrm{G}_{0} / \mathrm{G}_{1}, \mathrm{~S}$ and $\mathrm{G}_{2} / \mathrm{M}$ phase fraction.

Annexin V/PI analysis. The TACS ${ }^{\mathrm{TM}}$ Annexin V-FITC apoptosis detection kit (Trevigen, Gaithersburg, MD, USA) was used for the detection of early apoptotic and late apoptotic/necrotic cells according to the method previously described (26). Briefly, after treatment with $14 \mu \mathrm{M}$ of delphinidin for 12,24 and $48 \mathrm{~h}$, respectively, the cells were washed twice with PBS. Cells $\left(1 \times 10^{6}\right)$ were then resuspended in $100 \mu$ l Annexin V incubation reagent $(10 \mathrm{mM}$ HEPES $\mathrm{pH} 7.4,150 \mathrm{mM} \mathrm{NaCl}$, $5 \mathrm{mM} \mathrm{KCl}, 1 \mathrm{mM} \mathrm{MgCl} 2,1.8 \mathrm{mM} \mathrm{CaCl}_{2}, 5 \mu \mathrm{g} / \mathrm{ml} \mathrm{PI}$, and 
Annexin V-FITC). The cells were incubated in the dark for $15 \mathrm{~min}$ at room temperature, followed by the addition of $400 \mu \mathrm{l}$ binding buffer. Fluorescence intensities of FITC and PI were measured by a FACSCanto flow cytometer (Becton-Dickinson). A total of 30,000 events were obtained and data were analyzed by Diva software. Annexin V(-)PI(-), annexin V(+)PI(-), and Annexin $\mathrm{V}(+) \mathrm{PI}(+)$ cells were defined as viable, early apoptotic, and late apoptotic/necrotic cells, respectively.

Western blot analysis. Western blot analysis was carried out according to the methods previously described (28). Briefly, after separation of the proteins on an SDS polyacrylamide gel electrophoresis, followed by transferring to a nitrocellulose membrane, the protein bands were detected using the following primary antibodies and dilution ratios: rabbit antihuman caspase-3 (Enzo Life Sciences, New York, NY, USA) at 1:1,000; rabbit anti-human caspase-8 (BD Biosciences, Franklin Lakes, NJ, USA) at 1:4,000; rabbit anti-human caspase-9 (Cell Signaling Technology, Danvers, MA, USA) at 1:1,000; mouse anti-human Bid (BD Biosciences) at 1:1,000; and mouse anti-human $\beta$-actin (Sigma) at 1:5,000. Blotted protein bands were detected with respective horseradish peroxidase-conjugated secondary antibodies and an enhanced chemiluminescence (ECL) western blot analysis system (GE Healthcare, Buckinghamshire, UK).

Measurement of caspase-3, - 8 and -9 activities. Activity of caspase- $3,-8$ or -9 was measured using the caspase fluorometric assay kit (BioVision, Inc., Milpitas, CA, USA) according to the methods previously described (29). Protein $(50 \mu \mathrm{g} / 50 \mu \mathrm{l})$ was plated on a 96-well plate, followed by the addition of $50 \mu 1$ of $2 \mathrm{X}$ reaction buffer containing $10 \mathrm{mM}$ DTT to each sample, and then $5 \mu \mathrm{l}$ of $1 \mathrm{mM}$ caspase substrate (final concentration of $50 \mu \mathrm{M})$. After incubation at $37^{\circ} \mathrm{C}$ for $1 \mathrm{~h}$, fluorescent intensity was measured with a $400 \mathrm{~nm}$ excitation filter and $505 \mathrm{~nm}$ emission filter using a microplate reader (Safire).

Determination of loss of mitochondrial membrane potential $\left(\Delta \Psi_{m}\right) . \Delta \Psi \mathrm{m}$ was determined by flow cytometry after cell loading with Rhodamine 123 as previously described with modifications (26). After treatment with $14 \mu \mathrm{M}$ of delphinidin for 3, 6, 12 and $24 \mathrm{~h}$, respectively, the cells were washed with PBS, followed by incubation with $10 \mu \mathrm{M}$ Rhodamine 123 in PBS for $15 \mathrm{~min}$ in the dark at room temperature. The fluorescence intensities of Rhodamine 123 were measured by a FACSCanto flow cytometer (Becton-Dickinson). A total of 30,000 events were obtained and data were analyzed by Diva software.

Analysis of intracellular arsenic accumulation (As[i]). After exposure of NB4 cells to $2 \mu \mathrm{M} A s^{\mathrm{III}}$ alone or in combination with $8 \mu \mathrm{M}$ delphinidin for $0,1,3$ or $6 \mathrm{~h}$, the cells were washed three times with PBS and harvested in 2\% SDS solution. Protein concentrations were determined by Bradford's method using the protein assay dye reagent (Bio-Rad Laboratories, Hercules, CA, USA) according to the manufacturer's instructions, and using BSA as the standard. The As[i] was normalized by the amount of proteins and given as parts per billion (ppb) of arsenic per mg of proteins. The analysis of total arsenic was performed by inductively coupled plasma-mass spectrometry
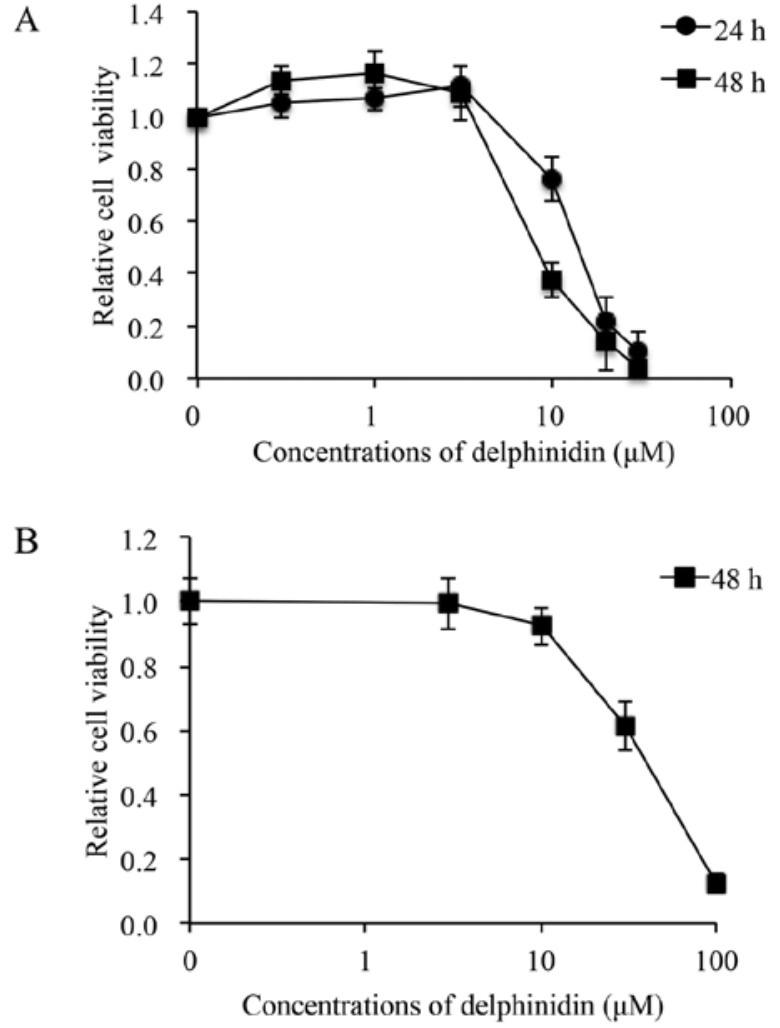

Figure 2. Cytotoxic effect of delphinidin against NB4 cells. (A) NB4 cells were treated with various concentrations of delphinidin $(0.3,1,3,10,20$ and $30 \mu \mathrm{M}$ ) for 24 and $48 \mathrm{~h}$. (B) PBMNCs were treated with various concentrations of delphinidin $(3,10,30$ and $100 \mu \mathrm{M})$ for $48 \mathrm{~h}$. Cell viability was determined by an XTT assay as described in Materials and methods. Data are shown as the mean \pm SD from three independent experiments. PBMNCs, peripheral blood mononuclear cells.

(ICP-MS) (Perkin-Elmer Sciex, Thornhill, ON, Canada) according to the methods previously reported $(7,27,30)$.

Statistical analysis. Experiments were independently repeated three times, and the results were shown as the mean \pm standard deviation (SD) of three assays. The Student's t-test was used to compare sample means from two groups, and one-way ANOVA followed by the Tukey's post test was used to compare sample means from more than three groups. $\mathrm{P}<0.05$ was considered to indicate a significant result.

\section{Results}

Cytotoxic effect of delphinidin against NB4 cells. Delphinidin exhibited dose- and time-dependent cytotoxic effects on NB4 cells after treatment with various concentrations of delphinidin $(0.3,1,3,10,20$ and $30 \mu \mathrm{M})$ for 24 and $48 \mathrm{~h}$ (Fig. 2A). When the concentration of delphinidin was increased to $10 \mu \mathrm{M}$, statistically significant differences were observed between the delphinidin-exposed and control groups (Fig. 2A). Furthermore, the $\mathrm{IC}_{50}$ values were 14.0 and $8.1 \mu \mathrm{M}$ for $24-$ and 48 -h treatment, respectively, calculated from the respective cell proliferation inhibition curve. On the other hand, after treatment with various concentrations of delphinidin $(3,10,30$ and $100 \mu \mathrm{M})$ for $48 \mathrm{~h}$, the apparent cytotoxicity of delphinidin was observed in the PBMNCs 

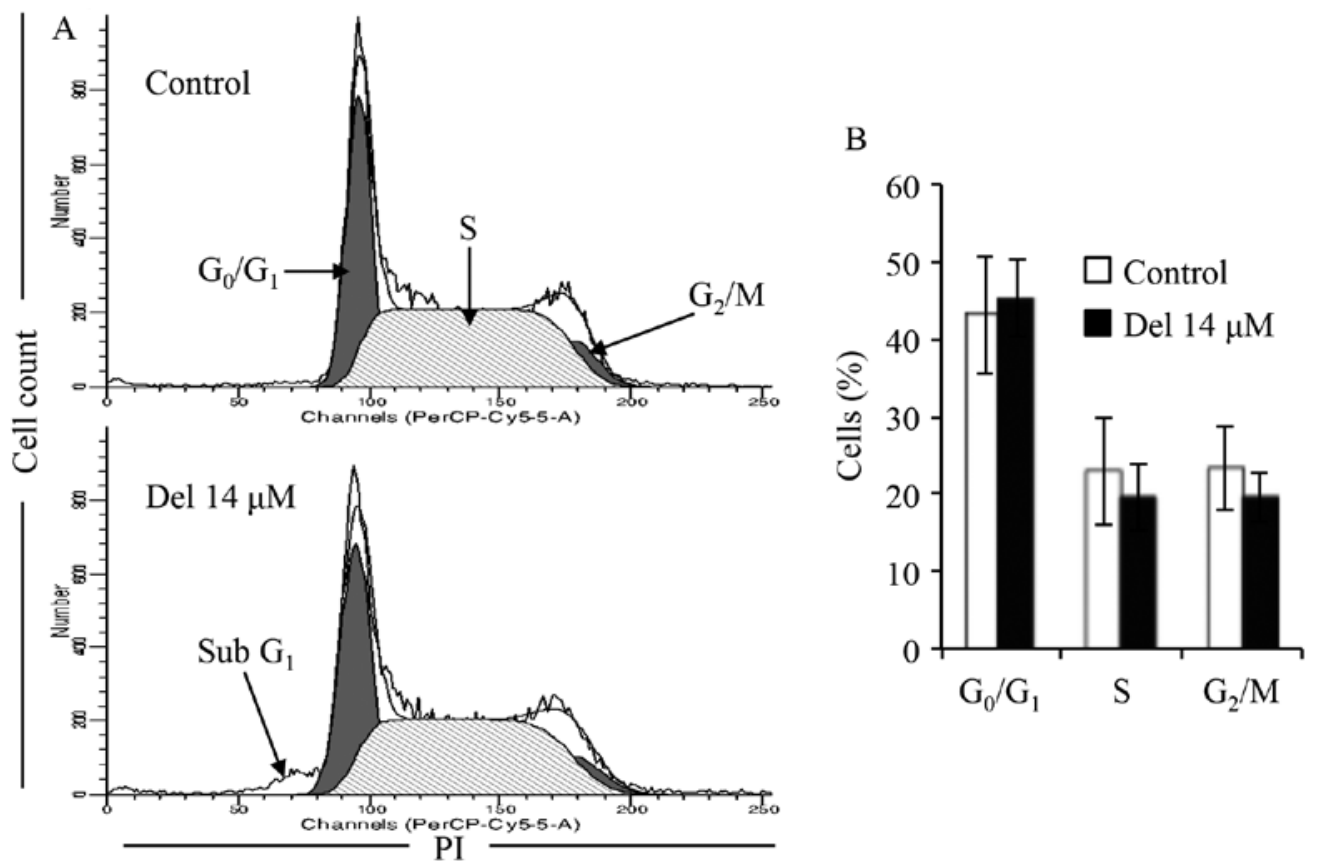

Figure 3. Effect of delphinidin on cell-cycle profiling of NB4 cells. After treatment with the $\mathrm{IC}_{50}$ value of delphinidin at $14.0 \mu \mathrm{M}$ for $24 \mathrm{~h}$, cell-cycle profiling was performed by a FACSCanto flow cytometer as described in Materials and methods. Analyzed data and profiles for each sub- $\mathrm{G}_{1}, \mathrm{G}_{0} / \mathrm{G}_{1}, \mathrm{~S}$, and $\mathrm{G}_{2} / \mathrm{M}_{\mathrm{Chase}}$ using Diva software and ModFit LT ${ }^{\mathrm{TM}}$ ver.3.0. are shown in the open and the gray area. Cells at S phase are shown as the shaded area. Representative FACS histograms from three independent experiments are shown in (A). The number of cells at each phase fraction calculated from (A) is shown in (B). Del, delphinidin.

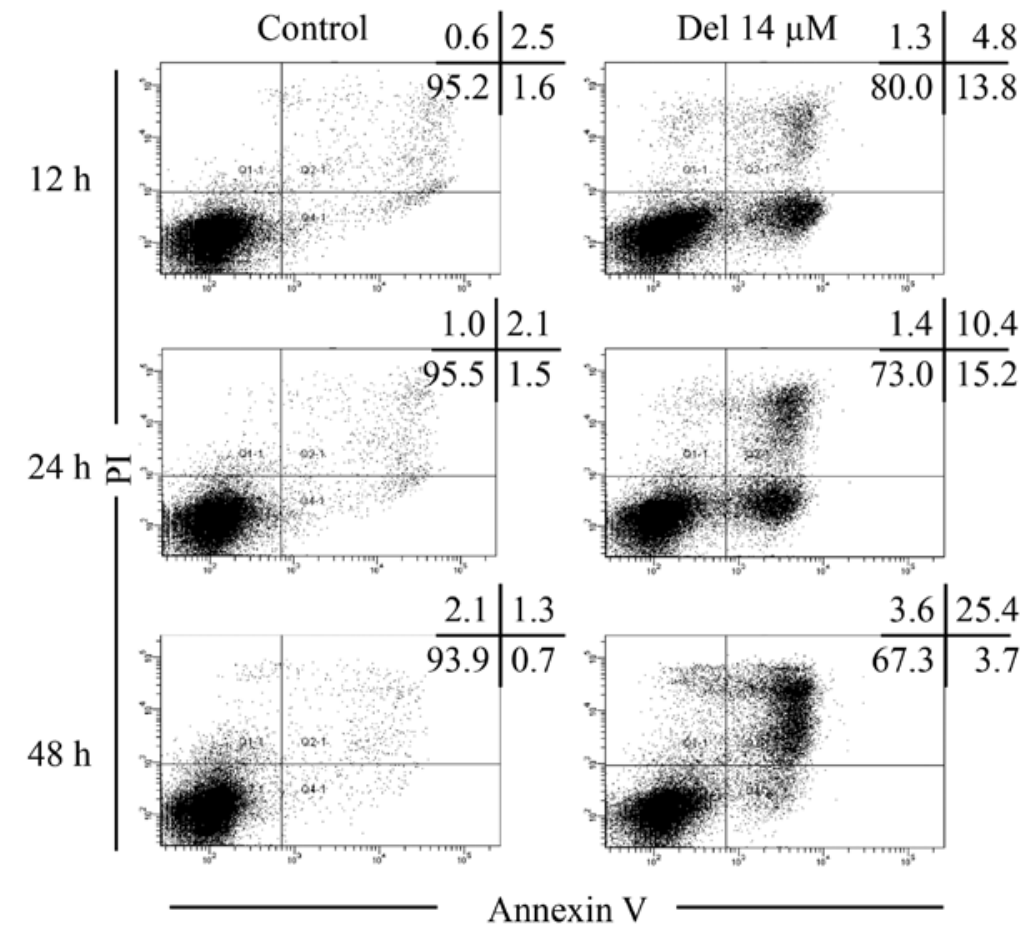

Figure 4. Apoptosis induction in NB4 cells treated with delphinidin. After treatment with $14.0 \mu \mathrm{M}$ delphinidin for 12,24 and $48 \mathrm{~h}$, the cells were stained with Annexin V-FITC and PI, and measured with a FACSCanto flow cytometer as described in Materials and methods. A total of 30,000 events were obtained and data were analyzed by Diva software. Annexin V(-)PI(-), Annexin V(+)PI(-), and Annexin V(+)PI(+) cells were defined as viable, early apoptotic, and late apoptotic/necrotic cells, respectively. The numbers in the upper-right corner of each dot plot show the percentage of Annexin V(-)PI(-), Annexin V(+)PI(-), Annexin $\mathrm{V}(+) \mathrm{PI}(+)$ and Annexin $\mathrm{V}(-) \mathrm{PI}(+)$ cells. Representative FACS dot plots from three independent experiments are shown. Del, delphinidin.

only when the concentration was $>10 \mu \mathrm{M}$, and the $\mathrm{IC}_{50}$ value of delphinidin was $39.7 \mu \mathrm{M}$ (Fig. 2B). These results showed that delphinidin exerted more potent cytotoxicity against
NB4 cells than normal PBMNCs. Therefore, subsequent experiments were conducted to clarify the details underlying delphinidin-induced cytotoxicity in NB4 cells following 
treatment with the $\mathrm{IC}_{50}$ value of delphinidin at $14.0 \mu \mathrm{M}$ for the indicated time-point.

Effect of delphinidin on the cell cycle profiling of NB4 cells. The flow cytometric analysis showed that almost no cell arrest was observed in NB4 cells, although there was a decrease in the number of cells in $\mathrm{S}$ and $\mathrm{G}_{2} / \mathrm{M}$ phases following treatment with $14.0 \mu \mathrm{M}$ delphinidin for $24 \mathrm{~h}$ (Fig. 3). An apparent increase in the number of cells in sub- $\mathrm{G}_{1}$ phase was observed, indicating apoptosis induction in NB4 cells treated with delphinidin (Fig. 3A).

Apoptosis induction in NB4 cells treated with delphinidin. After treatment with $14.0 \mu \mathrm{M}$ of delphinidin for 12, 24 and $48 \mathrm{~h}$, apoptosis was measured with FACS analysis. Consistent with cell-cycle results (Fig. 3A), the cells treated with $14.0 \mu \mathrm{M}$ delphinidin underwent early and late stage apoptosis in a time-dependent manner as compared with the control group, as demonstrated by the transition from Annexin V(-)PI(-) to Annexin V(+)PI(-), and then to Annexin V(+)PI(+) (Fig. 4). The transition of cells through these three stages clearly indicated the induction of apoptosis in NB4 cells treated with delphinidin.

Delphinidin-mediated caspase activation and Bid truncation in NB4 cells. After treatment of NB4 cells with $14.0 \mu \mathrm{M}$ of delphinidin for 1, 3, 6, 12 and $24 \mathrm{~h}$, western blot analysis was conducted to determine the activation of caspase-3, -8 , and -9 , as well as Bid truncation. As shown in Fig. 5A, the cleaved forms of caspase- 8 and -9 were observed as early as 1 -h postexposure to delphinidin and continued up to $24 \mathrm{~h}$, indicating the activation of caspase- 8 and -9 in the cells. Activation of caspase-3 was also confirmed based on the appearance of its cleaved form from 3 -h post-exposure and continued up to $24 \mathrm{~h}$ (Fig. 5A). Furthermore, an approximate 2- and 3- to 4-fold increase in the activity of caspase-3, -8 and -9 , respectively, was observed in NB4 cells after treatment for 24 and $48 \mathrm{~h}$, respectively (Fig. 5B). Moreover, it was confirmed that no alteration in caspase activation was observed in the control group cells between 24 - and 48-h treatment. Similar to the activation pattern of caspase- 8 and -9 , a substantial decrease in the expression level of Bid was observed as early as 1-h post-exposure, indicating its truncation in NB4 cells treated with delphinidin (Fig. 5A).

Delphinidin-induced loss of mitochondrial membrane potential $(\Delta \Psi m)$ in NB4 cells. After treatment with $14.0 \mu \mathrm{M}$ of delphinidin for 3, 6, 12 and $24 \mathrm{~h}$, Rhodamine 123, a cellpermeant cationic fluorescent dye, was used to assay $\Delta \Psi \mathrm{m}$ in NB4 cells. As shown in Fig. 6, only a modest decrease in $\Delta \Psi \mathrm{m}$ was observed at $3 \mathrm{~h}$ post-exposure, followed by a substantial time-dependent decrease in $\Delta \Psi \mathrm{m}$ in NB4 cells treated with delphinidin.

Enhanced cytotoxic effect of delphinidin in combination with $A s^{I I I}$ in NB4 cells. Since delphinidin exerted more potent cytotoxicity against NB4 cells than normal PBMNCs (Fig. 2), we examined the potential for the application of the combination of delphinidin and As ${ }^{\mathrm{III}}$, which has demonstrated notable clinical efficacy in the treatment of relapsed and refractory APL patients $(9,31)$. To clarify whether enhanced cytotoxicity was
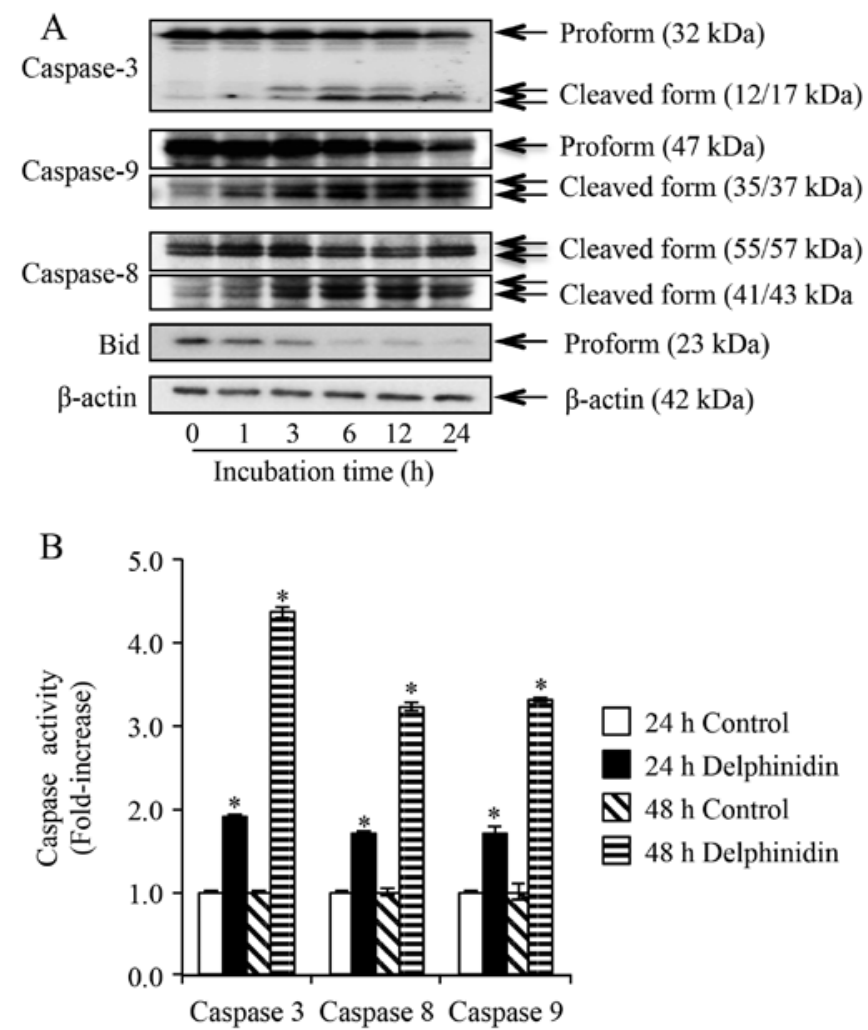

Figure 5. Delphinidin-mediated caspases activation and Bid truncation in NB4 cells. After treatment with $14.0 \mu \mathrm{M}$ delphinidin for 1, 3, 6, 12 and $24 \mathrm{~h}$, western blot analysis was conducted to determine the activation of (A) capase-3, -8 and -9 , as well as Bid truncation. (B) The activity of caspase- $3,-8$ and -9 in NB4 cells treated with $14.0 \mu \mathrm{M}$ delphinidin for 24 and $48 \mathrm{~h}$ was also measured using a caspase fluorometric assay kit as described in Materials and methods. Results are shown as the mean \pm SD from three independent experiments. Significant differences were observed between the control and delphinidin-treated groups $\left({ }^{*} \mathrm{P}<0.001\right.$ vs. control $)$

induced by the combination treatment, $8 \mu \mathrm{M}$ of delphinidin, which was estimated to inhibit $20 \%$ of cell proliferation in NB4 cells by the cell proliferation inhibition curve for $24 \mathrm{~h}$, was combined with As ${ }^{\mathrm{III}}$. After treatment with delphinidin $(8 \mu \mathrm{M})$ and $\mathrm{As}^{\mathrm{III}}[2 \mu \mathrm{M}$, concentrations achieved clinically (9)], alone or in combination, respectively, for $24 \mathrm{~h}$, cell viability was determined by XTT assay. As shown in Fig. 7A, cell viability significantly decreased to $77.5,83.3$ and $31.9 \%$ of the control when treated with delphinidin and As ${ }^{\mathrm{III}}$ either alone or in combination, respectively. In agreement with the results in Fig. 2B, $8 \mu \mathrm{M}$ of delphinidin did not exhibit cytotoxicity against PBMNCs. Although treatment with $2 \mu \mathrm{M}$ of $\mathrm{As}^{\mathrm{III}}$ alone reduced cell viability to $84.8 \%$ of the control in PBMNCs, a similar enhanced cytotoxic effect of delphinidin in combination with $\mathrm{As}^{\mathrm{III}}$ was not observed, indicating that the reduction in cell viability was primarily attributed to $\mathrm{As}^{\mathrm{III}}$ (Fig. 7B).

As[i] in NB4 cells treated with As ${ }^{I I I}$ alone or in combination with delphinidin. Arsenic uptake was measured to examine whether delphinidin affected As[i] in NB4 cells when combined with As ${ }^{\mathrm{III}}$. After exposure of NB4 cells to $2 \mu \mathrm{M} \mathrm{As}^{\mathrm{III}}$ alone or in combination with $8 \mu \mathrm{M}$ delphinidin for $0,1,3$ or $6 \mathrm{~h}$, As[i] was measured by ICP-MS. As shown in Fig. 8, the levels of As[i] increased with time in NB4 cells following treatment with $\mathrm{As}^{\mathrm{III}}$ alone. In comparison to treatment with $\mathrm{As}{ }^{\mathrm{III}}$ alone, 


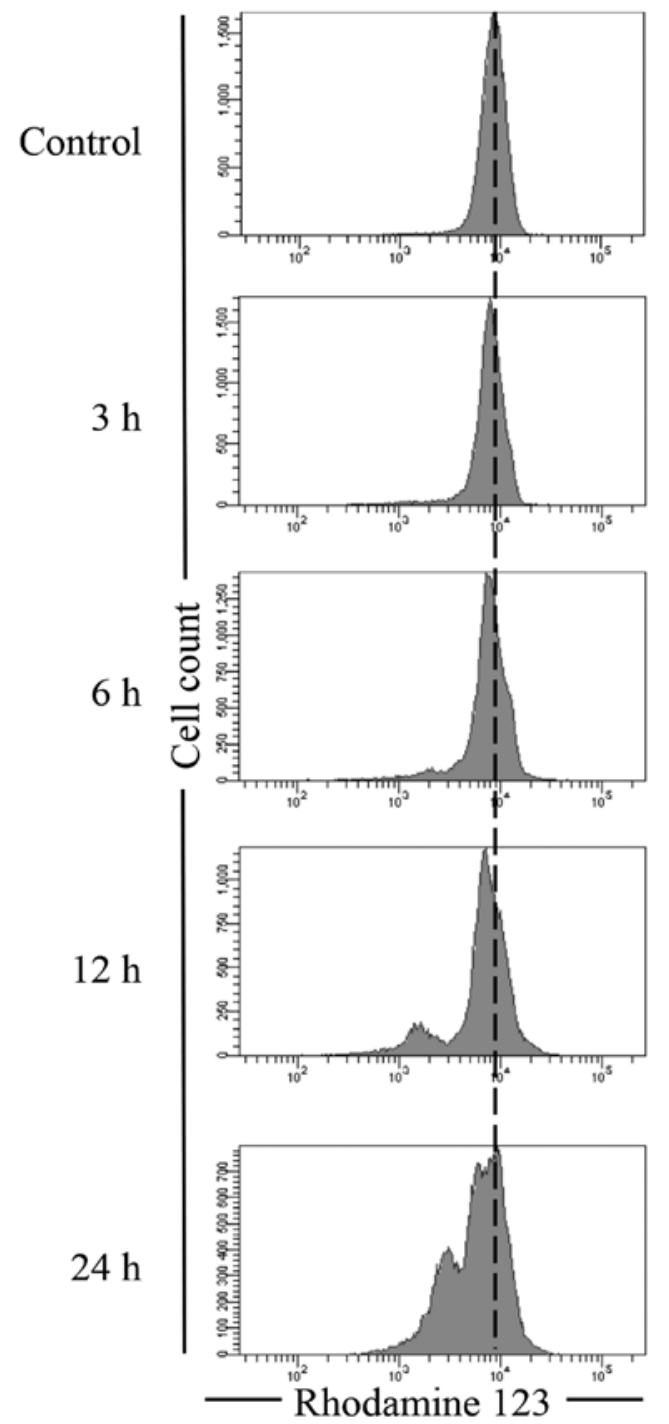

Figure 6. Delphinidin-induced loss of mitochondrial membrane potential $(\Delta \Psi \mathrm{m})$ in NB4 cells. After treatment with $14.0 \mu \mathrm{M}$ delphinidin for $3,6,12$ and $24 \mathrm{~h}$, the loss of $\Delta \Psi \mathrm{m}$ was determined using Rhodamine 123 by FACS analysis. Representative FACS histogram from three independent experiments is shown.

the levels of As[i] decreased slightly, but significantly, in the cells after treatment with $\mathrm{As}^{\mathrm{III}}$ in combination with delphinidin for 1 and $3 \mathrm{~h}$, and were restored at $6 \mathrm{~h}$ to the level of the group receiving $\mathrm{As}^{\mathrm{III}}$ alone.

\section{Discussion}

In the present study, we have demonstrated that delphinidin exhibited dose- and time-dependent cytotoxic effects on NB4 cells, and exerted more potent cytotoxicity against NB4 cells than normal PBMNCs. Similarly, delphinidin has been demonstrated to inhibit the cell growth of AU-565 and MCF-10A breast cancer cell lines, and to have only minimal effects on normal mammary epithelial 184A1 cells (16). Hafeez et al (15) have demonstrated that delphinidin induces a dose-dependent inhibition of cell growth in LNCaP, C4-2, 22Rv1 and PC3 human prostate cancer cell lines, without having any substantial effects on normal human prostate
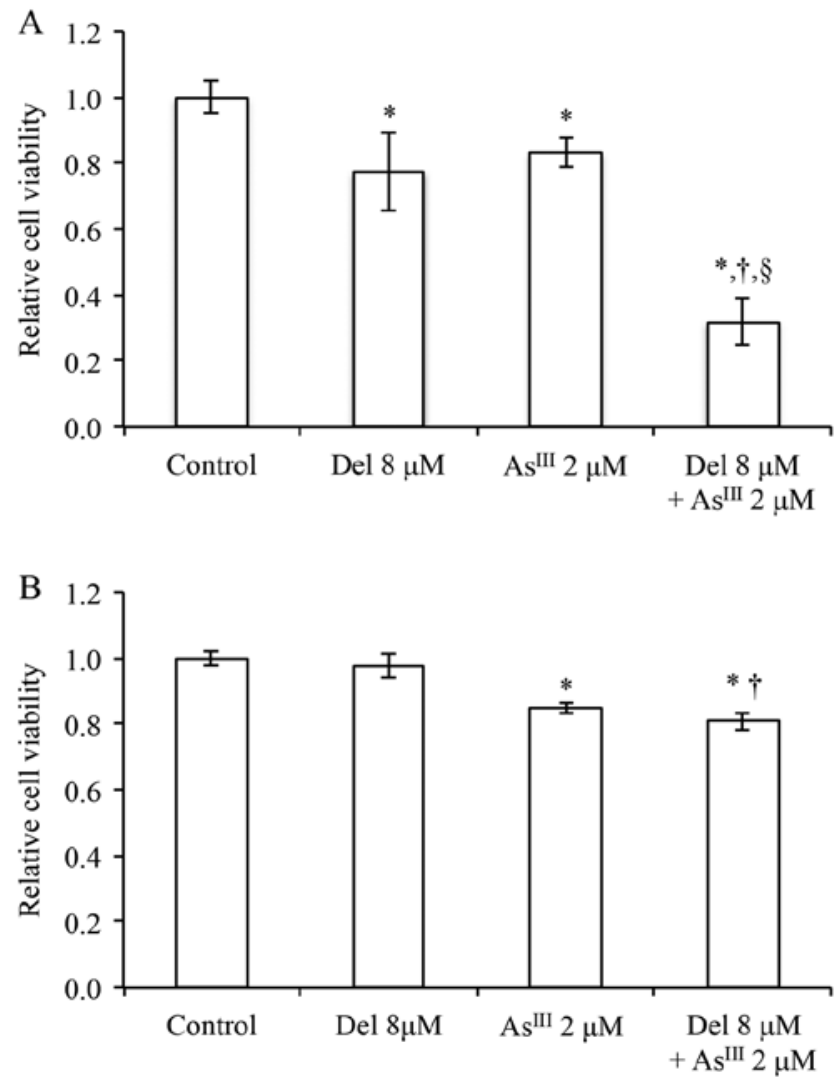

Figure 7. Enhanced cytotoxic effect of delphinidin in combination with $\mathrm{As}^{\mathrm{III}}$ in NB4 cells. Following treatment with $8 \mu \mathrm{M}$ delphinidin and $2 \mu \mathrm{M}$ $A s^{I I I}$, alone or in combination, respectively, for $24 \mathrm{~h}$, the cell viability of (A) NB4 and (B) PBMNCs was determined by XTT assay, respectively, as described in Materials and methods. Data are shown as the mean \pm SD from three independent experiments. Statistical analysis was conducted using one-way ANOVA followed by the Tukey's post test. $\mathrm{P}<0.05$ was considered as statistically significant ( ${ }^{*} \mathrm{P}<0.001$ vs. control; ${ }^{\dagger} \mathrm{P}<0.001$ vs. Del $8 \mu \mathrm{M}$; ${ }^{\S} \mathrm{P}<0.001$ vs. As ${ }^{\mathrm{III}} 2 \mu \mathrm{M}$ ). Del, delphinidin; PBMNCs, peripheral blood mononuclear cells.

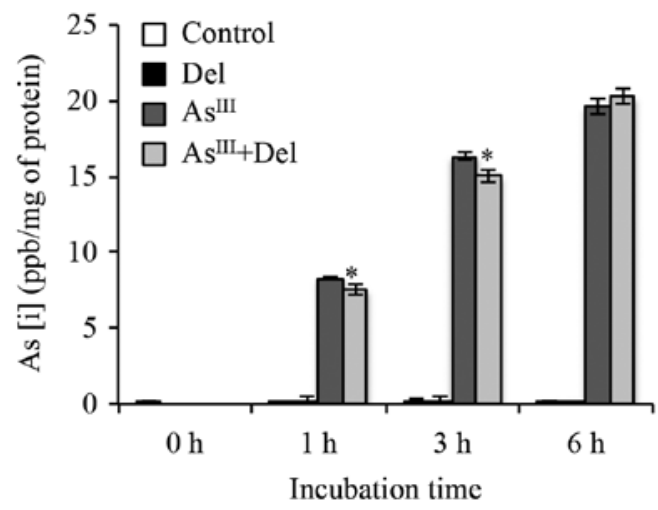

Figure 8. As[i] in NB4 cells treated with $\mathrm{As}^{\mathrm{III}}$ alone or in combination with delphinidin. After treatment with $8 \mu \mathrm{M}$ delphinidin and $2 \mu \mathrm{M} \mathrm{As}{ }^{\mathrm{III}}$, alone or in combination, respectively, for $0,1,3$ or $6 \mathrm{~h}, \mathrm{As}[\mathrm{i}]$ was measured by ICP-MS, as described in Materials and methods. Data are shown as the mean \pm SD from three independent experiments. $\mathrm{P}<0.05$ was considered as statistically significant ("P<0.05 vs. AsIII $2 \mu \mathrm{M})$. Del, delphinidin.

epithelial cells. Collectively, delphinidin seems to possess a selective cytotoxic activity against tumor cells rather than normal cells. 
Cell-cycle arrest is involved in the anti-proliferative effects of a large number of plant-derived agents including delphinidin in various solid tumor cells $(17,18)$. In the case of leukemic cells, it has been demonstrated that quercetin induces cell cycle arrest at $\mathrm{G}_{2} / \mathrm{M}$ phase in NB4 cells, but not in other leukemic cells such as U937 and HL-60 (12). Moreover, genistein has been demonstrated to provoke a doseand time-dependent accumulation of cells at $\mathrm{G}_{2} / \mathrm{M}$ phase in U937 cells (13). These findings suggest that the induction of cell cycle arrest is strongly dependent on the inducer and/or cell types. In the present study, we have demonstrated that almost no cell-cycle arrest, but a time-dependent apoptosis induction, was observed in NB4 cells treated with delphinidin, suggesting that the delphinidin-mediated cytotoxic effect was attributed to apoptosis induction rather than cell cycle arrest. It is well known that the aim of anticancer therapy is generally focused on apoptosis induction in premalignant and malignant cells (32). Our results thus raise a possibility that delphinidin may be developed as an effective chemopreventive and/or chemotherapeutic agent.

To clarify the molecular details of the apoptosis pathway, we focused on the activation of caspases including caspase- 3 , -8 and -9 , which are key players in two principal signaling pathways of apoptosis induction, known as the intrinsic and extrinsic pathways $(9,33)$. The intrinsic mechanism of apoptosis involves a disruption of the mitochondrial cell membrane, resulting in the loss of $\Delta \Psi \mathrm{m}$ associated with cytochrome $c$ release, followed by the activation of caspase-3 and -9 $(9,32,33)$. By contrast, the extrinsic pathway induced by death receptors, such as Fas and tumor necrosis factor receptor, is responsible for the activation of caspase- 8 accompanied by the activation of caspase- $3(9,32)$. In the present study, the activation of caspase- 8 and -9 was observed as early as 1-h post-exposure to delphinidin, followed by the activation of caspase-3 from 3-h post-exposure, suggesting the contribution of the intrinsic and extrinsic pathways to the delphinidin-triggered apoptosis induction in NB4 cells. We also demonstrated that a substantial decrease in the expression levels of Bid was observed as early as 1 -h post-exposure, the same time-point as the activation of caspase- 8 . Only a modest decrease in $\Delta \Psi \mathrm{m}$ was observed at 3-h post-exposure, followed by a substantial time-dependent decrease in $\Delta \Psi \mathrm{m}$ in delphinidin-treated NB4 cells. It is noteworthy that the caspase-8-mediated cleavage of Bid into a pro-apoptotic active truncated form provides the connection between the intrinsic and extrinsic pathway (34). It has become clear that truncated Bid translocates to the mitochondria and then leads to a decrease of $\Delta \Psi \mathrm{m}$, following the release of cytochrome $c$ from mitochondria to cytosol $(35,36)$. Taking the previous results and our observations into account, we suggest that truncated Bid, as a result of activation of caspase- 8 , contributes to the loss of $\Delta \Psi \mathrm{m}$, and further amplifies the apoptotic signal triggered by delphinidin in NB4 cells.

More importantly, we also demonstrated that delphinidin in combination with $\mathrm{As}^{\mathrm{III}}$ achieved an enhanced cytocidal effect against NB4 cells, but lesser on PBMNCs. Although the marked clinical efficacy of $A s^{\text {III }}$-based regimens against APL has been reported $(6,10)$, its side effects remain a serious concern and limit its clinical applications. The successful application of new As ${ }^{\mathrm{III}}$-based therapies may require the generation of sensitizing strategies to improve the efficacy of $\mathrm{As}^{\mathrm{III}}$, and consequently reduce the drug dose to clinically tolerable concentrations. Flavonoids such as quercetin and genistein have been reported to selectively potentiate $\mathrm{As}^{\mathrm{III}}$-induced apoptosis via ROS generation resulting from intracellular GSH depletion, and activation of the intrinsic and extrinsic apoptotic pathway in human leukemia cell lines such as HL-60, U937 and THP-1, but not in phytohemagglutininstimulated non-tumor peripheral blood lymphocytes $(12,13)$. Collectively, the present results suggest that delphinidin is a promising cancer chemopreventive agent candidate for enhancing the clinical efficacy of $\mathrm{As}{ }^{\mathrm{III}}$.

Based on an evaluation of the intracellular accumulation of Rhodamine $123 \mathrm{and} /$ or daunorubicin in multidrug-resistant cells expressing P-glycoprotein (Pgp) or non-Pgp multidrug drug resistance protein, flavonoids such as genistein have been demonstrated to inhibit these drug transporters, resulting in enhanced accumulation of these substrates $(37,38)$. However, in comparison to treatment with $\mathrm{As}^{\mathrm{III}}$ alone, the level of As[i] was decreased by the addition of delphinidin in the first $3 \mathrm{~h}$ of treatment, and returned at $6 \mathrm{~h}$ to the level of the group receiving $\mathrm{As}^{\mathrm{III}}$ alone. These results suggested that the enhanced cytotoxicity effect of delphinidin in combination with $\mathrm{As}^{\mathrm{III}}$ in NB4 cells may not be attributed to the alterations of As[i]. However, detailed experimental studies focusing on the mechanisms underlying the enhanced cytotoxic effect are needed.

In conclusion, to the best of our knowledge, we have demonstrated for the first time that delphinidin showed selective cytotoxic effects against NB4 cells, but minimal effects on PBMNCs. We have also shown that the intrinsic and extrinsic pathways linked by Bid contributed to the cytotoxicity. More importantly, delphinidin selectively sensitized the cells to $\mathrm{As}^{\mathrm{III}}$, resulting in the enhancement of $\mathrm{As}^{\mathrm{III}}$ cytotoxicity by strengthening intrinsic/extrinsic pathway-mediated apoptosis induction, rather than affecting the levels of As[i]. These observations may offer a rationale for the use of delphinidin to improve the clinical efficacy of $\mathrm{As}^{\mathrm{III}}$.

\section{Acknowledgements}

We thank Professor Steven R. Kayser of UCSF School of Pharmacy for the critical reading of this manuscript. The present study was supported in part by grants from the Japan China Medical Association to Bo Yuan.

\section{References}

1. de Thé H, Chomienne C, Lanotte M, Degos L and Dejean A: The $t(15 ; 17)$ translocation of acute promyelocytic leukaemia fuses the retinoic acid receptor alpha gene to a novel transcribed locus. Nature 347: 558-561, 1990.

2. Goddard AD, Borrow J, Freemont PS and Solomon E: Characterization of a zinc finger gene disrupted by the $t(15 ; 17)$ in acute promyelocytic leukemia. Science 254: 1371-1374, 1991.

3. Tong JH, Dong S, Geng JP, Huang W, Wang ZY, Sun GL, Chen SJ, Chen Z, Larsen CJ and Berger R: Molecular rearrangements of the MYL gene in acute promyelocytic leukemia (APL, M3) define a breakpoint cluster region as well as some molecular variants. Oncogene 7: 311-316, 1992.

4. Fujisawa S, Ohno R, Shigeno K, Sahara N, Nakamura S, Naito K, Kobayashi M, Shinjo K, Takeshita A, Suzuki Y, et al: Pharmacokinetics of arsenic species in Japanese patients with relapsed or refractory acute promyelocytic leukemia treated with arsenic trioxide. Cancer Chemother Pharmacol 59: 485-493, 2007. 
5. Kiguchi T, Yoshino Y, Yuan B, Yoshizawa S, Kitahara T, Akahane D, Gotoh M, Kaise T, Toyoda $\mathrm{H}$ and Ohyashiki K: Speciation of arsenic trioxide penetrates into cerebrospinal fluid in patients with acute promyelocytic leukemia. Leuk Res 34: 403-405, 2010

6. Shen ZX, Chen GQ, Ni JH, Li XS, Xiong SM, Qiu QY, Zhu J, Tang W, Sun GL, Yang KQ, et al: Use of arsenic trioxide $\left(\mathrm{As}_{2} \mathrm{O}_{3}\right)$ in the treatment of acute promyelocytic leukemia (APL): II. Clinical efficacy and pharmacokinetics in relapsed patients. Blood 89: 3354-3360, 1997.

7. Yoshino Y, Yuan B, Miyashita SI, Iriyama N, Horikoshi A, Shikino O, Toyoda $\mathrm{H}$ and Kaise T: Speciation of arsenic trioxide metabolites in blood cells and plasma of a patient with acute promyelocytic leukemia. Anal Bioanal Chem 393: 689-697, 2009.

8. Iriyama N, Yoshino Y, Yuan B, Horikoshi A, Hirabayashi Y, Hatta Y, Toyoda $\mathrm{H}$ and Takeuchi J: Speciation of arsenic trioxide metabolites in peripheral blood and bone marrow from an acute promyelocytic leukemia patient. J Hematol Oncol 5: 1, 2012.

9. Yuan B, Yoshino Y, Kaise T and Toyoda H: Application of arsenic trioxide therapy for patients with leukemia. In: Biological Chemistry of Arsenic, Antimony and Bismuth. Sun H (ed). John Wiley and Sons, Ltd., Chichester, pp263-292, 2011.

10. Soignet SL, Maslak P, Wang ZG, Jhanwar S, Calleja E, Dardashti LJ, Corso D, DeBlasio A, Gabrilove J, Scheinberg DA, et al: Complete remission after treatment of acute promyelocytic leukemia with arsenic trioxide. N Engl J Med 339: 1341-1348, 1998.

11. Surh YJ: Cancer chemoprevention with dietary phytochemicals. Nat Rev Cancer 3: 768-780, 2003.

12. Ramos AM and Aller P: Quercetin decreases intracellular GSH content and potentiates the apoptotic action of the antileukemic drug arsenic trioxide in human leukemia cell lines. Biochem Pharmacol 75: 1912-1923, 2008

13. Sánchez Y, Amrán D, Fernández $\mathrm{C}$, de Blas E and Aller P. Genistein selectively potentiates arsenic trioxide-induced apoptosis in human leukemia cells via reactive oxygen species generation and activation of reactive oxygen species-inducible protein kinases (p38-MAPK, AMPK). Int J Cancer 123 1205-1214, 2008

14. Hou DX, Fujii M, Terahara N and Yoshimoto M: Molecular mechanisms behind the chemopreventive effects of anthocyanidins. J Biomed Biotechnol 2004: 321-325, 2004.

15. Hafeez BB, Siddiqui IA, Asim M, Malik A, Afaq F, Adhami VM, Saleem M, Din M and Mukhtar H: A dietary anthocyanidin delphinidin induces apoptosis of human prostate cancer PC3 cells in vitro and in vivo: Involvement of nuclear factor-kappaB signaling. Cancer Res 68: 8564-8572, 2008.

16. Afaq F, Zaman N, Khan N, Syed DN, Sarfaraz S, Zaid MA and Mukhtar H: Inhibition of epidermal growth factor receptor signaling pathway by delphinidin, an anthocyanidin in pigmented fruits and vegetables. Int J Cancer 123: 1508-1515, 2008.

17. Yun JM, Afaq F, Khan N and Mukhtar H: Delphinidin, an anthocyanidin in pigmented fruits and vegetables, induces apoptosis and cell cycle arrest in human colon cancer HCT116 cells. Mol Carcinog 48: 260-270, 2009

18. Lazzè MC, Savio M, Pizzala R, Cazzalini O, Perucca P Scovassi AI, Stivala LA and Bianchi L: Anthocyanins induce cell cycle perturbations and apoptosis in different human cell lines. Carcinogenesis 25: 1427-1433, 2004

19. Cvorovic J, Tramer F, Granzotto M, Candussio L, Decorti G and Passamonti S: Oxidative stress-based cytotoxicity of delphinidin and cyanidin in colon cancer cells. Arch Biochem Biophys 501: $151-157,2010$.

20. Suzuki R, Tanaka M, Takanashi M, Hussain A, Yuan B, Toyoda $\mathrm{H}$ and Kuroda M: Anthocyanidins-enriched bilberry extracts inhibit 3T3-L1 adipocyte differentiation via the insulin pathway, Nutr Metab (Lond) 8: 14, 2011.

21. Kausar H, Jeyabalan J, Aqil F, Chabba D, Sidana J, Singh IP and Gupta RC: Berry anthocyanidins synergistically suppress growth and invasive potential of human non-small-cell lung cancer cells. Cancer Lett 325: 54-62, 2012.
22. Aiyer HS, Warri AM, Woode DR, Hilakivi-Clarke L and Clarke R: Influence of berry polyphenols on receptor signaling and cell-death pathways: Implications for breast cancer prevention. J Agric Food Chem 60: 5693-5708, 2012.

23. Hou DX, Ose T, Lin S, Harazoro K, Imamura I, Kubo M, Uto T, Terahara N, Yoshimoto M and Fujii M: Anthocyanidins induce apoptosis in human promyelocytic leukemia cells: Structureactivity relationship and mechanisms involved. Int J Oncol 23: 705-712, 2003

24. Katsube N, Iwashita K, Tsushida T, Yamaki K and Kobori M Induction of apoptosis in cancer cells by Bilberry (Vaccinium myrtillus) and the anthocyanins. J Agricultural and Food Chem 51: 68-75, 2003.

25. Hou DX, Tong X, Terahara N, Luo D and Fujii M: Delphinidin 3-sambubioside, a Hibiscus anthocyanin, induces apoptosis in human leukemia cells through reactive oxygen species-mediated mitochondrial pathway. Arch Biochem Biophys 440: 101-109, 2005.

26. Kon A, Yuan B, Hanazawa T, Kikuchi H, Sato M, Furutani R, Takagi $\mathrm{N}$ and Toyoda $\mathrm{H}$ : Contribution of membrane progesterone receptor $\alpha$ to the induction of progesterone-mediated apoptosis associated with mitochondrial membrane disruption and caspase cascade activation in Jurkat cell lines. Oncol Rep 30: 1965-1970, 2013.

27. Yoshino Y, Yuan B, Kaise T, Takeichi M, Tanaka S, Hirano T, Kroetz DL and Toyoda H: Contribution of aquaporin 9 and multidrug resistance-associated protein 2 to differential sensitivity to arsenite between primary cultured chorion and amnion cells prepared from human fetal membranes. Toxicol Appl Pharmacol 257: 198-208, 2011.

28. Yuan B, Ohyama K, Bessho T and Toyoda H: Contribution of inducible nitric oxide synthase and cyclooxygenase- 2 to apoptosis induction in smooth chorion trophoblast cells of human fetal membrane tissues. Biochem Biophys Res Commun 341: 822-827, 2006.

29. Imai M, Yuan B, Kikuchi H, Saito M, Ohyama K, Hirobe C, T Oshima T, Hosoya T, Morita H and Toyoda H: Growth inhibition of a human colon carcinoma cell, COLO 201, by a natural product, Vitex agnus-castus fruits extract, in vivo and in vitro. Adv Biol Chem 2: 20-28, 2012.

30. Iriyama N, Yuan B, Yoshino Y, Hatta Y, Horikoshi A, Aizawa S, Takeuchi J and Toyoda $\mathrm{H}$ : Aquaporin 9, a promising predictor for the cytocidal effects of arsenic trioxide in acute promyelocytic leukemia cell lines and primary blasts. Oncol Rep 29: 2362-2368, 2013.

31. Wang ZY and Chen Z: Acute promyelocytic leukemia: From highly fatal to highly curable. Blood 111: 2505-2515, 2008.

32. Bremer E, van Dam G, Kroesen BJ, de Leij L and Helfrich W: Targeted induction of apoptosis for cancer therapy: Current progress and prospects. Trends Mol Med 12: 382-393, 2006.

33. Ryter SW, Kim HP, Hoetzel A, Park JW, Nakahira K, Wang X and Choi AM: Mechanisms of cell death in oxidative stress. Antioxid Redox Signal 9: 49-89, 2007.

34. Kantari $\mathrm{C}$ and Walczak H: Caspase- 8 and bid: Caught in the act between death receptors and mitochondria. Biochim Biophys Acta 1813: 558-563, 2011

35. Li H, Zhu H, Xu CJ and Yuan J: Cleavage of BID by caspase 8 mediates the mitochondrial damage in the Fas pathway of apoptosis. Cell 94: 491-501, 1998.

36. Luo X, Budihardjo I, Zou H, Slaughter C and Wang X: Bid, a $\mathrm{Bcl} 2$ interacting protein, mediates cytochrome c release from mitochondria in response to activation of cell surface death receptors. Cell 94: 481-490, 1998.

37. Castro AF and Altenberg GA: Inhibition of drug transport by genistein in multidrug-resistant cells expressing P-glycoprotein. Biochem Pharmacol 53: 89-93, 1997.

38. Kitagawa S: Inhibitory effects of polyphenols on P-glycoproteinmediated transport. Biol Pharm Bull 29: 1-6, 2006. 